\title{
BMJ Open Four delays of child mortality in Rwanda: a mixed methods analysis of verbal social autopsies
}

\author{
Sanam Roder-DeWan, ${ }^{1,2}$ Neil Gupta, ${ }^{3,4}$ Daniel M Kagabo, ${ }^{4}$ \\ Lameck Habumugisha, ${ }^{4}$ Evrard Nahimana, ${ }^{4}$ Catherine Mugeni, ${ }^{5}$ Tatien Bucyana, ${ }^{5}$ \\ Lisa R Hirschhorn ${ }^{6,7}$
}

To cite: Roder-DeWan S, Gupta N, Kagabo DM, et al. Four delays of child mortality in Rwanda: a mixed methods analysis of verbal social autopsies. BMJ Open 2019;9:e027435. doi:10.1136/ bmjopen-2018-027435

- Prepublication history for this paper is available online. To view these files, please visit the journal online (http://dx.doi. org/10.1136/bmjopen-2018027435).

Received 24 October 2018 Revised 31 January 2019 Accepted 2 April 2019

Check for updates

(C) Author(s) (or their employer(s)) 2019. Re-use permitted under CC BY-NC. No commercial re-use. See rights and permissions. Published by BMJ.

For numbered affiliations see end of article.

Correspondence to Dr Sanam Roder-DeWan; roderdewan@mail.harvard.edu

\section{ABSTRACT}

Objectives We sought to understand healthcare-seeking patterns and delays in obtaining effective treatment for rural Rwandan children aged $1-5$ years by analysing verbal and social autopsies (VSA). Factors in the home, related to transport and to quality of care in the formal health sector (FHS) were thought to contribute to delays. Design We collected quantitative and qualitative crosssectional data using the validated 2012 WHO VSA tool. Descriptive statistics were performed. We inductively and deductively coded narratives using the three delays model, conducted thematic content analysis and used convergent mixed methods to synthesise findings.

Setting The study took place in the catchment areas of two rural district hospitals in Rwanda-Kirehe and Southern Kayonza. Participants were caregivers of children aged 1-5 years who died in our study area between March 2013 and February 2014.

Results We analysed 77 VSAs. Although $74 \%$ of children $(\mathrm{n}=57)$ had contact with the FHS before dying, most $(59 \%, n=45)$ died at home. Many caregivers $(44 \%$, $\mathrm{n}=34$ ) considered using traditional medicine and 23 (33\%) actually did. Qualitative themes reflected difficulty recognising the need for care, the importance of traditional medicine, especially for 'poisoning' and poor perceived quality of care. We identified an additional delay-phase IV-which occurred after leaving formal healthcare facilities. These delays were associated with caregiver dissatisfaction or inability to adhere to care plans. Conclusion Delays in deciding to seek care (phase I) and receiving quality care in FHS (phase III) dominated these narratives; delays in reaching a facility (phase II) were rarely discussed. An unwillingness or inability toadhere to treatment plans after leaving facilities (phase IV) were an important additional delay. Improving quality of care, especially provider capacity to communicate danger signs/ treatment plans and promote adherence in the presence of alternative explanatory models informed by traditional medicine, could help prevent childhood deaths.

\section{BACKGROUND}

Rwanda has reduced under-five (U5) mortality by more than two-thirds since 2000, one of only 12 low-income countries to achieve Millennium Development Goal (MDG) four. ${ }^{1-3}$ This progress, although

\section{Strengths and limitations of this study}

- The large qualitative and quantitative dataset allowed us to explore delays in healthcare-seeking among caregivers of children aged 1-5 years who died in this area of Rwanda.

- Our analysis led to the identification of an important additional source of delays that occurred after children left formal sector healthcare. We call these 'phase IV delays'.

- As is the nature of qualitative research, these findings cannot be generalised beyond the study population, but may be used to guide similar explorations in comparable samples.

- By characterizing a fourth delay, we adapt the three delays model of maternal mortality for use in understanding childhood mortality.

exceptional by most measures, mirrors a global trend towards reduced childhood mortality and an epidemiological transition away from the most easily preventable causes of death. ${ }^{4}$ As proficiency is gained in tackling the 'low-hanging fruit' of child health, health systems must turn their attention to solving the more complex problems that remain.

Despite Rwanda's remarkable progress, a child is still 10 times more likely to die before their fifth birthday in Rwanda than in most high-income countries. ${ }^{5}$ Evidence from other low-income countries suggests that the majority of these deaths will occur outside of a health facility and that late care-seeking is a significant contributing factor. ${ }^{6}$ Understanding family and community contexts will therefore be important for improvement. ${ }^{89}$ What beliefs and behaviours exist in homes and communities that delay care-seeking? What barriers do caregivers face when they decide to seek care and what challenges might an increasingly capable but complex health system pose for them?

These questions may best be answered by viewing healthcare-seeking pathways and the 
health system from the perspective of its users, an area of scholarship that is poorly represented in the literature in low-income and middle-income countries (LMIC). ${ }^{10}$ This study aims to address the gap in knowledge by analysing verbal and social autopsy (VSA) data collected following all deaths of children aged 1-5 years in two rural districts in Rwanda.

\section{METHODS}

\section{Setting}

During the study period, there were 23 health centres (HC) in Kirehe and Southern Kayonza serving a population of 538405 . HCs were staffed by nurses who provided inpatient and outpatient services. ${ }^{11} 12$ Community health workers (CHWs) provided integrated community case management of paediatric illnesses (c-IMCI) ${ }^{13}$ They diagnosed and treated pneumonia, diarrhoea and malaria, monitored malnutrition and made referrals. An estimated average of one CHW served 50 people under age 5 ; there were two c-IMCI-trained CHWs per village. ${ }^{13} 14$ Kirehe was served by one district hospital and Kayonza by two. The study was conducted in the catchment area of one hospital in Kirehe and another in Kayonza. Area households in the two districts were located a median $3.5 \mathrm{~km}$ from their closest HC. ${ }^{11}$ Community-based health insurance (CBHI, also referred to as 'Mutuelle de Santé' or 'mutuelle') was available in the study districts and achieved over 90\% coverage in Rwanda overall (Makaka et al, 2012). ${ }^{15}$ The catchment area for this study was rural and the majority of families relied on subsistence agriculture. Paved roads connected the main towns, and unpaved roads extended to most communities. Homes were predominantly made of natural materials such as earth and thatch and few communities had access to electricity. According to the 2014 Rwandan Demographic and Health Survey, nearly $40 \%$ of the population lived below the poverty line, although nearly all women in Kirehe and Kayonza worked in agriculture. Educational attainment was low in both areas, with most women not having completed primary school. ${ }^{16}$

\section{Study design}

Data were collected through VSAs with caregivers of 259 U5s who died between March 2013 and February 2014. VSA is a process used to assign causes of death in cases where no standard autopsy was done and social autopsy augments the structured interview of a verbal autopsy with open-ended questions about the beliefs, decisions and perspectives of those who cared for the decedent. ${ }^{10}$ 17-24 Quantitative and qualitative data were collected during one visit with a family. Deaths were identified through health records, Rwandan Ministry of Health (RMOH) reporting systems and the Monitoring of Vital Events Using Information Technology programme in which CHWs reported vital events by telephone. CHWs then helped locate families, and families who consented were interviewed between 3 weeks and 1 year after the death. The minimum waiting period of 3 weeks was selected considering the Rwandan custom of a formal 1-week mourning period and literature from other countries suggesting that several weeks is an appropriate delay. ${ }^{2526}$ Importantly, families could decline participation and could choose a time for the interview if they consented. This paper is a subanalysis of VSA data of children between the ages of 1 year and 5 years. This age range was chosen because it includes children with shared developmental characteristics (eg, the ability to crawl/walk), clinical characteristics (eg, causes of pneumonia) and social experiences (eg, not being in primary school).

Quantitative data were collected using the validated WHO 2012 verbal autopsy semi-structured interview tool (InterVA4 $^{27}$ and supplemented by questions from the RMOH's Death Audit Tool and the 2010 Rwanda Demographic and Health Survey. Trained interviewers used handheld electronic devices and conducted semi-structured interviews in the local language, Kinyarwanda. Informants were asked to describe events surrounding the death of the child. Segments during which interviewees expanded on symptoms, decision-making, care-seeking and perceptions of care received were transcribed and then back-transcribed from Kinyarwanda to English for quality and accuracy review.

\section{Patient and public involvement}

The research question was informed by the work of Partners in Health/Inshuti Mu Buzima (PIH/IMB), which has supported the RMOH to strengthen healthcare delivery and systems in Kirehe and Southern Kayonza districts since 2005. This VSA project was part of a larger initiative to better understand and reduce U5 mortality. Patients were not involved in the recruitment to and conduct of the study, nor were they involved in the design of the study. However, as a service delivery organisation, PIH/ IMB has a deep experience with patients and their families/caregivers that helped shape the study. Aggregated early results were shared with the $\mathrm{MOH}$ and IMB in a timely manner to facilitate improved healthcare delivery.

\section{Analysis}

We used the three delays model ${ }^{28}$ as a framework to begin our thematic content analysis. This model was originally developed to understand maternal mortality. ${ }^{28}$ Phase I delays relate to deciding to seek care, phase II delays occur while trying to reach a facility and phase III delays occur after arrival at a facility in the form of poor quality of care. We use the Lancet Global Health Commission on High Quality Health Systems framework to understand high-quality care. Specifically, high-quality care includes competent care and systems, positive user experience as well as better health, confidence in the system and economic benefit. ${ }^{29}$

A mix of inductive and deductive coding was used to develop a codebook, ${ }^{30}$ which was discussed and revised by an interdisciplinary team of researchers, physicians and public health professionals. A subset of interviews 
(11) were double coded to ensure inter-rater reliability and then the codebook was applied to the dataset until saturation of codes was reached at 77 interviews. Iterative thematic analysis using coding, recoding, categorisation and reorganisation was used to further develop the themes and generate hypotheses. Dedoose was used for qualitative and mixed methods analysis (V.7.5.9, SocioCultural Research Consultants, Los Angeles, California, USA).

The most likely cause of death (COD) was determined using InterVA4. ${ }^{27} \mathrm{COD}$ and sociodemographic variables from verbal autopsies were analysed using descriptive statistics. Quantitative analytics were performed using STATA V.14 (StataCorp, College Station, Texas, USA).

Associations between descriptive variables and qualitative themes were explored using a convergent mixed methods approach. ${ }^{31}$ This approach is recommended by experts to better understand complex phenomenon, such as care-seeking behaviour, because it helps uncover patterns that may not have been accessible through only quantitative data analysis or only qualitative data analysis. ${ }^{32}$ Excerpts were first organised by phase of delay and then divided by quantitative variables. These variables were chosen based on hypotheses which were generated during the qualitative analysis of the interviews. Hypotheses included 1) maternal education impacts careseeking by giving caregivers more access to accurate health information, 2) children who died at home experienced more phase I delays, 3) less common causes of death are associated with more phase III delays. Thematic analysis of these subgroups of excerpts was conducted to identify divergent themes. Interviews were coded and analysed until saturation of codes was achieved, ie, saturation was achieved when no new codes or ideas were identified. ${ }^{33}$

Verbal consent was deemed permissible by two ethics review boards. A consent form was read to potential participants by Kinyarwanda-speaking data collectors who also answered questions. Participants were asked to verbally confirm that the consent was understood. Data collectors were trained in sensitivity, patience and consideration with families who had lost a child. Each interview was assigned a number that matched with caregiver identifying information and was stored in a separate file in a secure location. No individual identifiers were recorded on the data collection forms.

\section{RESULTS}

We identified 259 deaths of children aged 1-5 years (table 1). Saturation of codes was reached at 77 interviews. The average age at death of the 77 children was 2.5 years. The majority were male $(57 \%)$ and $27 \%$ of mothers had no formal education. The average age of mothers of the deceased was 31 years. One-quarter of informants (29\%) reported having no health insurance for the family. The leading COD was malaria (39\%), then respiratory illness (14\%) and acute abdomen (severe abdominal pain usually requiring surgery) at $14 \%$.
Most children received some care from the formal health sector (FHS) $-61 \%$ from a $\mathrm{HC}$ and $55 \%$ from a CHW. A CHW was the first point of contact for $46 \%$. Nearly half of the caregivers (34 of 77) considered consulting a traditional healer during the illness leading to the index child's death; $33 \%$ actually did. The majority (59\%) of children died at home.

Phase I delays, were raised during 54 VSAs. Caregivers, most commonly mothers, frequently described 'confusion' and 'surprise' about their child's illness and said that they did not know what to do or when to seek care. They also described domestic responsibilities that constrained the ability to closely monitor children. For example, as women worked on their farms, older children were left to tend younger children (table $2 \mathrm{~A}$ ).

The majority $(63 \%, \mathrm{n}=34)$ of VSA cases describing phase I delays also discussed traditional medicine (TM), primarily for the diagnosis of 'poisoning' which was described as being caused by 'nasty people' who wanted to do harm. The diagnosis was confirmed when a traditional healer successfuly indcued vomiting or diarrhoea with a liquid medication. Traditional healers were consulted either in conjunction with the FHS (medical pluralism) or exclusively. Some respondents reported using TM to 'clear' the poison so that the FHS could be effective; others tried all available options concurrently. Exclusive use of TM usually occurred if the caregiver was certain about the diagnosis of poisoning (table 2B).

The majority of this subgroup of respondents (19/34) indicated that only TM could treat poisoning. Beliefs and practices that were associated with exclusive use of TM for poisoning included 'admitting' severely ill children with poisoning to the house of a traditional healer and believing that FHS care for poisoned children, especially in the form of an injection, would kill the child (table 2B).

Previous experiences with the health system or CBHI (being rejected for lack of insurance or inability to pay out-of-pocket) shaped care-seeking decisions. Even those that did have CBHI experienced administrative challenges to maintaining coverage. Beliefs about the quality of the health system also informed decisions to seek care (table 2C).

Phase II delays were raised spontaneously by 4 of 77 informants. Transport barriers included drivers refusing critically ill children and cost (table 2D). Many informants mentioned waiting until morning to travel, but the safety of travelling at night was not discussed directly. These informants may be referring to phase II delays, but this cannot be determined from the narratives. Some informants mentioned bypassing the closest facility and going to one they believed would provide higher quality care.

Phase III delays were described in 57 of 77 (74\%) cases. Despite Rwandan policy stating that no critically ill child should be turned away, five respondents reported being denied appropriate treatment in the FHS due to inability to pay (table 2E). Nearly all third-phase interviews mentioned poor quality of care (table $2 \mathrm{~F}$ ). A lack of FHS equipment, supplies, medicine or providers 
Table 1 Characteristics of paediatric autopsy cases in two rural districts of Rwanda, 2013-14

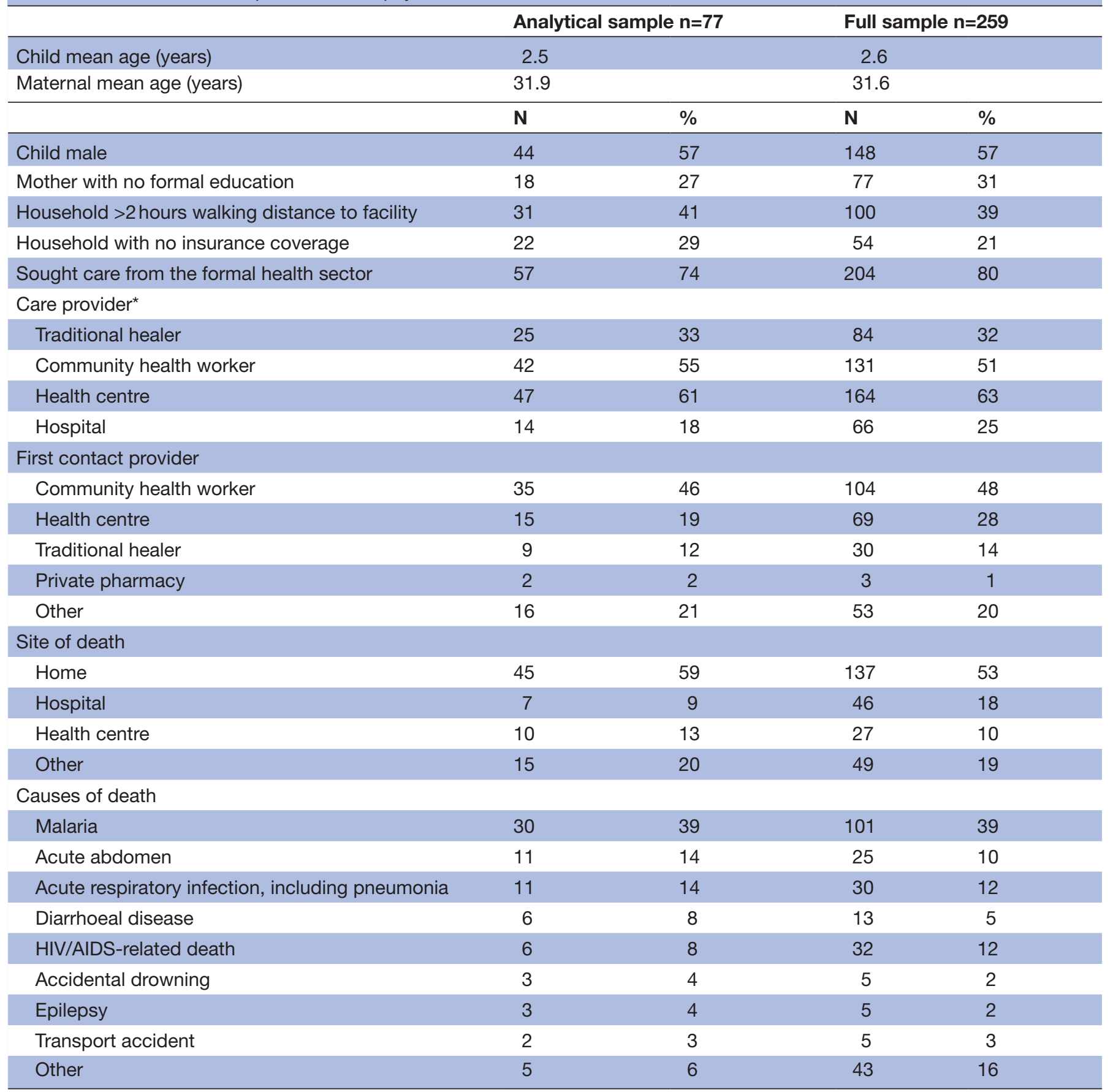

*May see multiple types of provider. The most likely cause of death was determined using InterVA4. ${ }^{27}$

were reported by very few informants $(n=6)$ and the majority of these excerpts related to CHWs. People describe 'neglect', being 'ignored', being 'reprimanded' or 'shown contempt'. Long wait times were frequently mentioned. Leaving the FHS not knowing a child's diagnosis or having a treatment plan, was common. Respondents reported poor provider technical skills at the FHS. Informants also described positive interactions with healthcare professionals who 'immediately' provided care or were empathic (table 2G), or went out of their way to help. Services were sometimes described as 'good' and 'proper'.

Informants reported barriers to successful care and treatment that did not fall into the three phases during 28 VSAs. These delays occurred after a child left the formal sector and were related to the willingness or capacity of caregivers to adhere to FHS treatment plans. We are calling these 'phase IV delays' (figure 1). Dissatisfaction with outcomes of care in the FHS (failed treatment or inconclusive tests) led families to abandon the 
Table 2 Key themes and supporting excerpts

Key theme Excerpts

A. Constrained capacity to identify or understand illness

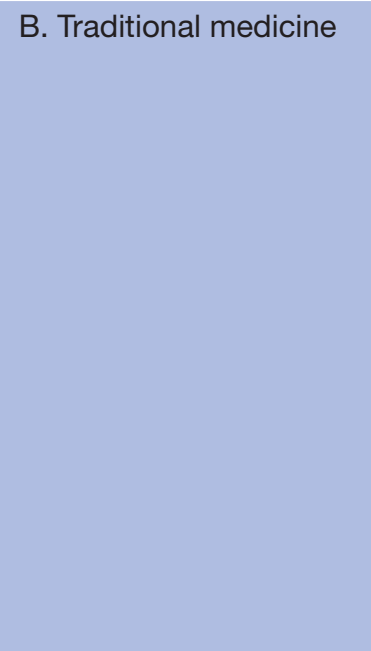

C. Pre-existing beliefs about the health system

i. Her death confused me to some extent. I woke up in the morning and went to wash my clothes. When I came back, I washed her too-it was my first time to lose a child, so I was ignorant of what had happened-when I washed her, she didn't cry. (Parent of girl aged 1 year who died of malaria)

ii. The death of the child should be known by his sister but, unfortunately, she is a child as well. (Parent of boy aged 2 years who died of malaria)

i. ...we took the child to traditional healers who told me that the child had been poisoned. They kept giving the child herbal medications, promising me that the child would recover from poisoning. Despite this promise, the child's abdomen kept swelling and I thought to myself, "I have to take the child to the health facility". I took the child to (health facility $x$ ) and when I arrived, they put the child on supplemental oxygen therapy for nearly 3 weeks but the child's condition never improved. (Parent of boy aged 1 year who died of pneumonia)

ii. As the other traditional healers had given the child medications which caused the child to vomit poison, I chose to take him back home in the hope that I would take him to (the health facility) and that it would be easy for them to help the child recover as the child had vomited the poison. After returning home, I immediately took him to the health facility but the child died on my way before reaching the health facility. (Parent of boy aged 2 years who died of diarrhoea)

iii. But as I told you, the child was poisoned. This is why I saw no need to take her to the health facility. I took her to the traditional healer and she died at the house of the traditional healer. (Parent of girl aged 2 years who died of malaria)

iv. I refrained from taking the child to the health facility because I knew full well that many poisoned children had immediately died at the health facility after being given an injection. (Parent of girl aged 3 years who died of trauma)

i. However, as we had no mutuelle, we were afraid of taking the baby to the health facility. I think this is the possible cause of the baby's death. (Parent of boy aged 3 years who died of an acute abdomen)

ii. When you are not enrolled, you are obliged to wait and you may even die there. (Parent of boy aged 1 year who died of malaria)

iii. I don't know what they are always busy doing! They are distracted by their own businesses! It is not easy to consult the health professional at (health facility X). (Parent of boy aged 2 years who died of an acute abdomen)

iv. We are offered quality service at (health facility $X$ ) even if it is far. If we do not go to (health facility $Y$ ) it is not due to the distance but rather to poor service. (Parent of boy aged 3 years who died of asthma)

Phase II

D. Transportation challenges i. I thought of going to [HF101] but this required hiring a moto taxi and, in our village, moto taxi drivers will not accept to transport you if you have a dying patient! (Parent of boy aged 2 years who died of an acute abdomen)

ii. Unfortunately, on the date of the appointment, I didn't have any money at all, I didn't even have transportation ticket to go to (the health facility). (Parent of boy aged 1 year who died of AIDS)

\section{Phase III}

E. Financial barriers at point-of-care i. (The healthcare worker) then asked me, "Are you enrolled in mutuelle de santé? If you're not enrolled in mutuelle de santé, I can't do anything to help you". (Parent of girl aged 3 years who died of pneumonia)

ii. As he wasn't enrolled in mutuelle de santé, they obliged us to pay Rwf 3000 before receiving him despite his being in a critical condition. (Parent of boy aged 1 year who died of diarrhoea)

iii. They refused to give me the transfer and the ambulance, simply because I didn't have money. So, they told me that they would give the child treatments. They gave her the treatments and then she died after a while. (Parent of girl aged 1 year who died of pneumonia) 
Table 2 Continued

\begin{tabular}{|c|c|}
\hline Key theme & Excerpts \\
\hline F. Poor quality of care & $\begin{array}{l}\text { i. I went to see a male CHW but I found that he was not around. I went to see another CHW and } \\
\text { met him, but he told me "I don't have treatments. Yesterday I gave the last ones to a child who } \\
\text { was ill". (Family of girl aged } 1 \text { year who died of malaria) } \\
\text { ii. In fact they gave her a treatment when it was almost dawning. So, they gave her an injection } \\
\text { and then, after a while-maybe they had gone to treat other patients - the child died. (Parent of } \\
\text { girl aged } 1 \text { year who died of pneumonia) } \\
\text { iii. Frankly speaking, there are instances where one goes to the health facility and your child's } \\
\text { condition gets worse instead of improving because health professionals sometimes neglect } \\
\text { patients. They sometimes delay providing us with treatment and show contempt for us thinking } \\
\text { that they have more education than we have and they consider us peasants from rural areas. } \\
\text { They even happen to deny us healthcare. (Parent of girl aged } 2 \text { years who died of epilepsy) } \\
\text { iv. They didn't reveal to me anything regarding the child's illness. They only prescribed some } \\
\text { tablets for the child. (Parent of boy aged } 3 \text { years who died of malaria) } \\
\text { v. When I arrived there, health professionals were there. I said to one of them "As you can see, } \\
\text { my child is in a critical condition. You should attend to him/her as a matter of urgency". He/she } \\
\text { replied, "Under the current rules, no one can be allowed to go straight to the front of the queue. } \\
\text { You have to bear with me and accept to queue". As I was queuing, the child immediately died } \\
\text { in my arms...I thought that health professional has to be blamed for my child's death. (Parent of } \\
\text { boy aged } 1 \text { year who died of malaria) } \\
\text { vi. They discharged her and they told me to go home and give her pills. They discharged her } \\
\text { although it was obvious that she was still very sick. (Parent of girl aged } 2 \text { years who died of } \\
\text { malaria) }\end{array}$ \\
\hline
\end{tabular}

G. Positive experiences with FHS i. There was a health professional by the name of ' $X$ ' who was loved by all community members. When a patient was not enrolled in the community-based health insurance scheme, she volunteered to pay for her medical bills for the patient to repay after a certain period of time. (Parent of girl aged 4 years who died of diarrhoea)

ii. They properly care for patients and give them useful advice. (Parent of girl aged 4 years who died of epilepsy)

\section{Phase IV}

H. Dissatisfaction leads to traditional medicine

i. they gave me small tablets for the child. I gave the tablets to the child, but it didn't work. Seeing that, we decided to take the child to traditional healers. (Parent of boy aged 2 years who died of malaria)

ii. ... As people often say, "you use tablets and if the child is not cured you tell yourself the baby must have been poisoned". (Parent of girl aged 3 years who died of pneumonia)

iii. ... As the tablets that we had received from the health facility hadn't helped the child to recover, and instead caused the child's condition to deteriorate, I thought the child had an illness that would be treated by traditional healers and hence chose to return to traditional healers. (Parent of boy aged 1 year who died of AIDS)

I. Home treatment plan failure i. I: Is it easy for you to access the meds once the doctor has prescribed them for you? R: It is a challenge because you cannot afford buying meds if you are not enrolled in the communitybased health insurance scheme. (Parent of boy aged 1 year who died of malaria)

ii. They gave me another appointment but told me that I had to pay bus fares on my own. And when I remembered the kind of life I had lived there, the medications that were prescribed to the child, the food and the financial means all that required, I noticed I was unable to secure all the money needed and I refrained from returning there. But apart from that, I could also see that the child had finished her journey on the earth. (Parent of girl aged 3 years who died of pneumonia)

iii. He spent 1 week and 1 day without crying. Although they discharged us, he hadn't cried yet, even once. "Once he arrives in a cold place, he will cry", they told me as they discharged us. We spent a whole week before he cried. We noticed that the child was wasting away day after day. When I went to have him weighed, he would weigh 2 kilograms today, and next time he would weigh 1 kilogram and some grams. (Parent of boy aged 1 year who died of AIDS) formal sector and seek care from traditional healers (table $2 \mathrm{H})$.

In seven cases, FHS personnel referred families to TM because poor treatment response was attributed to poisoning. Limited capacity to adhere to FHS treatment plans was linked to financial barriers or poor communication; caregivers lacked clear instructions on how to administer treatments or when to follow-up. Families 
$1^{\text {st }}$ Delay

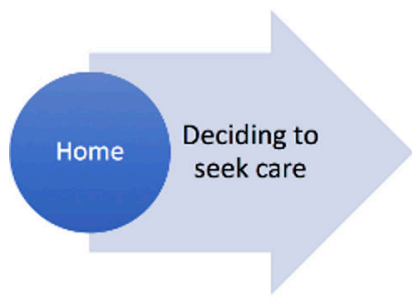

$N=54$ 2nd Delay

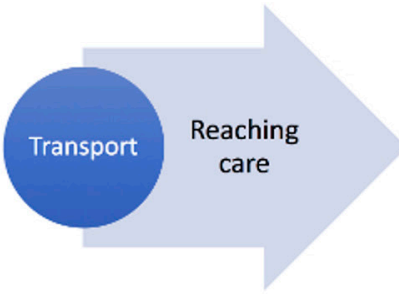

$\mathrm{N}=4$ 3rd Delay

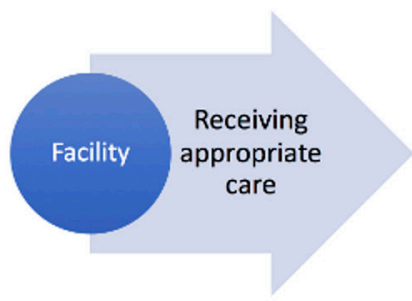

$N=57$ 4th Delay

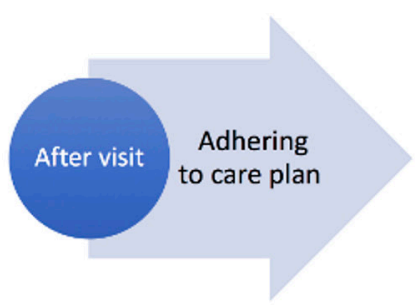

$N=28$

\section{$\mathrm{N}=77$ Interviews}

Figure 1 Four phases of delay. The graphic illustrates four phases of delay, starting with the first delay in deciding to seek care. Once decisions to seek care have been made, phase II delays in reaching formal care may be experienced. Those who arrive at a facility may experience phase III delays in receiving timely and appropriate care. The fourth phase occurs after patients have left formal care and involves challenges in adhering to the prescribed care plan.

were further challenged by needing to make multiple trips to FHS facilities (table 2I).

A hypothesis-driven mixed methods analysis revealed several additional themes. First, formal maternal education was associated with more active care-seeking language: "I decided", "I asked myself", "I had the child tested", "I suspected". Those without formal education disproportionately described delaying decisions in order to seek advice (table 3 ).

Second, children who died outside of a facility were not more likely to live far away from a HC or discuss phase II delays but were more likely to have died while caregivers were 'preparing' to go the FHS. This theme is not present in the subset of children that died in the FHS. Many caregivers of children who died at home actively made decisions to keep children at home if they believed that death was imminent; death at home appeared to be a preference. Those that did make it to a provider in the FHS but still had a child who died elsewhere, described issues with adherence to formal sector provider recommendations and follow-up; $88 \%$ of children whose caregivers discussed phase IV delays did not die in the FHS (table 4).

Finally, an analysis of excerpts by COD helped shed light on the fourth phase of delay (table 5). Although diversion to the informal sector occurred across all causes of death, the majority of cases of healthcare providers referring patients to traditional healers were in children who died of something other than malaria. Those who died of malaria had caregivers who described receiving 'tablets', waiting for them to take effect and having a child either die during treatment or in the care of a traditional healer because the treatments were perceived to be ineffective. They told of hesitating to take their child back to a facility despite recognising a lack of improvement during treatment. Whether this is because clear instructions for follow-up were not given or not understood cannot be determined from the data. Sometimes this hesitation came with an expressed fear of being judged for coming back too soon. Children without the diagnosis of malaria were less likely to have been given 'tablets' and more likely to experience delays after leaving an $\mathrm{HC}$ related to searching for a treatment from multiple formal facilities or from informal providers. Their decisions to seek alternatives were more likely to come immediately after leaving the treatment facility.

\section{DISCUSSION}

We analysed VSAs of 77 children aged 1-5 years in rural Rwanda and found that care-seeking was dominated by challenges in deciding to seek care (phase I) and in receiving high-quality care in the FHS (phase III). Our respondents rarely mentioned challenges in reaching a facility (phase II), although it is unclear whether the common experience of waiting until morning to travel was related to difficulty securing transport. In addition to the three classic delays, we identified a domain that occurred after sick children visited the FHS; phase IV delays. These children were sent home after an interaction with the FHS only to experience delays in follow-up care or adherence to treatment .

Phase IV delays were related to caregiver dissatisfaction or inability to adhere to care plans and often involved decisions to abandon formal sector care in favour of traditional medicine. This phase was identified and characterised through the qualitative analysis of narratives and is supported by descriptive data showing that $74 \%$ of children in our dataset had contact with the FHS, but $59 \%$ died at home. Phase IV delays were closely linked to the ability of providers to communicate care plans and danger signs, a shortcoming that is particularly dangerous in the presence of a robust traditional medicine system that caregivers can turn to if interactions with formal care are unsatisfactory or if the child is not improving as expected. The most common COD in this sample, malaria, appeared to be associated with fourth phase delays caused by receiving treatment but not 
Table 3 Phase I mixed methods themes and excerpts for maternal education

\begin{tabular}{|c|c|c|}
\hline & No formal maternal education & Some formal maternal education \\
\hline $\begin{array}{l}\text { Phase I excerpts by } \\
\text { maternal education }\end{array}$ & $\begin{array}{l}\text { Those who were with me, told me, } \\
\text { "Hurry up and, if he is still breathing } \\
\text { by the time you reach home, take } \\
\text { him immediately to the health facility } \\
\text { for them to find out the cause of the } \\
\text { child's death". (Parent of boy aged } 2 \\
\text { years who died of malaria) } \\
\text { "Let's go to see the father's child } \\
\text { in the farm so that he can help } \\
\text { me to take the child to the health } \\
\text { facility and to avoid that the child's } \\
\text { condition to deteriorate at home". } \\
\text { (Parent of girl aged } 4 \text { years who } \\
\text { died of malaria) } \\
\text { - I ran to the other neighbours who } \\
\text { were digging the fields and told } \\
\text { them, "Look! My child is dying and } \\
\text { h/s was healthy when I brought } \\
\text { him". (Parent of boy aged } 2 \text { years } \\
\text { who died of malaria) } \\
\text { - If I had known what illness the } \\
\text { child had I would have sought } \\
\text { treatment for the child. Some of my } \\
\text { neighbours could say that the child } \\
\text { was suffering from malnutrition while } \\
\text { others suspected the child had been } \\
\text { given poison. People in rural areas } \\
\text { are always inclined to speculate on } \\
\text { all that happens. (Parent of girl aged } \\
4 \text { years who died of AIDS) } \\
\text { - I sought advice from my fellow } \\
\text { mothers asking them, "My child has } \\
\text { a horrible smell in his nose. What } \\
\text { can I do?" (Parent of boy aged } 1 \\
\text { year who died of AIDS) }\end{array}$ & $\begin{array}{l}\text { Seeing that, I asked myself the following question: } \\
\text { why is my child passing such things in stool while } \\
\text { I've administered medications to the child? I put the } \\
\text { child on my back and came back home thinking that, } \\
\text { "Let me administer the medications to the child. If the } \\
\text { medications don't work, I will take the child to traditional } \\
\text { healers for them to find out what illness the child has". } \\
\text { (Parent of boy aged } 1 \text { year who died of malaria) } \\
\text {-When the child started getting ill, I had the child tested } \\
\text { for a folk illness known as uburo. I first took the child } \\
\text { to the traditional healer and then to the health facility. } \\
\text { (Parent of boy aged } 3 \text { years who died of malaria) } \\
\text { The child did not have any accident. I thought my child } \\
\text { was given poison by malicious people, who did so } \\
\text { secretly during our visit. (Parent of boy aged } 2 \text { years who } \\
\text { died of an acute abdomen) } \\
\text { It wasn't until late that night that I suspected that the } \\
\text { child was given poison. However, I said to myself, "I } \\
\text { need to take the child to the health facility first because } \\
\text { it might be that the child has abdominal pain because } \\
\text { of malaria. If I arrive at the health facility and the child } \\
\text { tests negative for malaria, I will decide to take her to } \\
\text { traditional healers". The child died before taking any } \\
\text { medications. (Parent of girl aged } 3 \text { years who died of an } \\
\text { acute abdomen) } \\
\text { - One evening in that same year, the child developed a folk } \\
\text { illness known as igishikuzi. Seeing that, I administered } \\
\text { meds to the child. After taking the meds, the child } \\
\text { moderately recovered. As the child appeared to have } \\
\text { moderately recovered, I decided to leave home for work. } \\
\text { As I was preparing to leave, the child's illness suddenly } \\
\text { came back again. After realising that it was the same } \\
\text { illness, I thought to myself, "I have to give the child the } \\
\text { meds I have given him before". As I was preparing for } \\
\text { going to pick up meds for the child, he immediately died. } \\
\text { (Parent of boy aged } 2 \text { years who died of epilepsy) }\end{array}$ \\
\hline
\end{tabular}

knowing when to return if treatment was not perceived to be effective.

The majority of deaths were not associated with a single delay (box 1). This finding is consistent with published literature on the three delays in maternal and child health. ${ }^{9284}$ Families experienced complex care pathways that often began with partial information about child health and required the ability to negotiate competing explanatory models. ${ }^{35}$ Explanatory models are socioculturally informed systems that explain illness and healing; in this population, 'poisoning' appears to be a dominant construct. Those that did reach the FHS were sometimes turned away for financial reasons. Although some informants described positive experiences with the FHS, many did not. Children died while caregivers waited and families left facilities without knowing why their child was sick or when to return. They made decisions to use TM or visited many FHS facilities. The complexity of care navigation was particularly challenging for families who struggled with intersectional causes of disadvantage such as poverty and limited education.

A preference for dying at home, possibly due to indirect costs of facility death, may have contributed to the high percent of children who died at home (59\%). Caregivers of children who died at home frequently described children dying while preparing to leave for the FHS suggesting that the urgency of the illness was not well understood. Finally, TM was used by one-third of families and even recommended by FHS providers possibly augmenting out-of-facility death rates. If poisoning was 'confirmed' (often when a traditional healer induced vomiting), some caregivers only used TM regardless of illness severity. Several practices made exclusive (rather than complementary) TM use more likely; several critically ill children in this sample were 'admitted' to the homes of traditional healers for more intense treatment and some informants believed that a poisoned child would be killed if treated in the FHS. This exclusive pattern of TM use is found in the literature on epilepsy and tuberculosis in Rwanda. ${ }^{36} 37$ 
Table 4 Phase I mixed methods themes and excerpts for place of death

\begin{tabular}{|c|c|c|}
\hline & Did not die in a facility & Died in a facility \\
\hline $\begin{array}{l}\text { Phase I excerpts by } \\
\text { place of death }\end{array}$ & 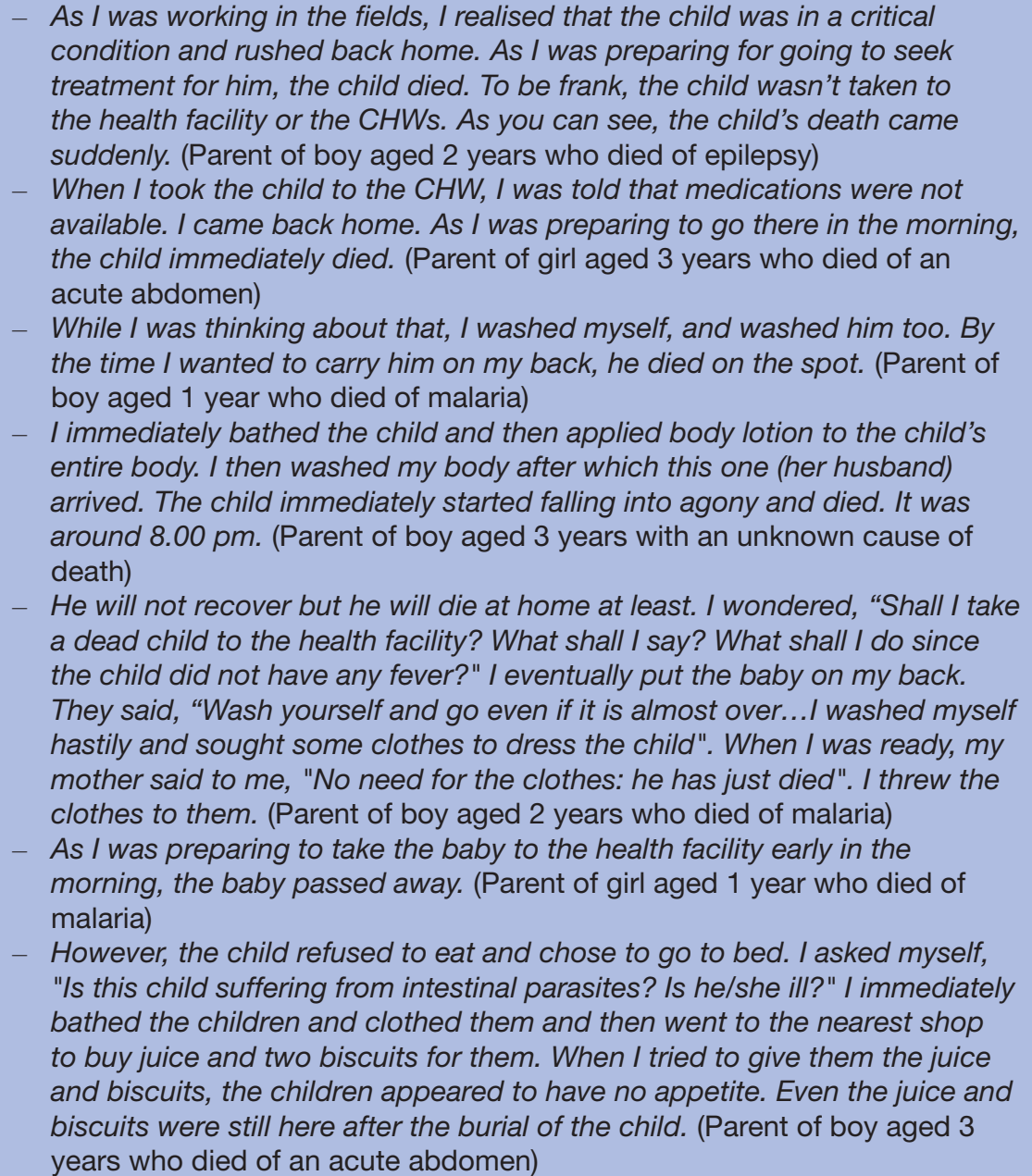 & Theme not present \\
\hline
\end{tabular}

Our data do not allow us to determine which symptoms are locally understood as indicative of poisoning in children, but according to Taylor (1988), the syndrome overlaps closely with features of clinical dehydration. Perhaps the non-specific nature of symptoms of poisoning contributes to the widespread use of TM in our study population.

Having TM as an alternative to shape an individual's explanatory model ${ }^{35}$ was particularly important when caregivers were not satisfied with the care that they received at the FHS. A large portion of fourth phase delays involved abandoning FHS treatment plans in favour of TM. Limited literature is available on the nature or role of TM in Rwanda, due in part to only very recent efforts to recognise and integrate this sector into the health system (Government of Rwanda, 2012). A qualitative study of TM providers and their role in treating pregnant women estimated that there are up to two traditional providers in each village in Rwanda and that they are usually older women who inherited the profession from their mothers. ${ }^{38}$ Only one study was identified that specifically describes a Rwandan concept of poisoning. ${ }^{39}$ That work characterises poisoning as a humour that acts through the digestive tract and decreases blood volume, a description that seems largely consistent with our findings.

In addition to helping us understand care-seeking in the community, our data also describe a health system from the perspective of its users. Many informants consulted a CHW as a first source of care, as recommended by the RMOH model of primary care. This shows that the population accepts this cadre as an integral part of the Rwandan healthcare system. However, families also encountered problems with CHWs-the majority of reports about limited medications or human resources in our dataset were about CHWs. These issues might make CHWs a source of delay rather than an expansion of the healthcare web in Rwanda.

The experience of care at facilities is a significant challenge to informants in this dataset. These phase III themes are framed by the classic work on quality of care by Avedis Donabedian of structure/inputs, processes and outcomes. ${ }^{40}$ The procedural elements of care (both technical and interpersonal) are far more likely to be raised by our informants then the structure or inputs of the FHS. Our informants describe how this quality impacts 
Table 5 Phase IV mixed methods themes and excerpts for malaria diagnosis

\begin{tabular}{|c|c|c|}
\hline & Malaria & Diagnosis other than malaria \\
\hline $\begin{array}{l}\text { Phase IV excerpts by } \\
\text { cause of death (COD) } \\
\text { (malaria) }\end{array}$ & $\begin{array}{l}\text { When I arrived, they gave me small tablets } \\
\text { for the child. I gave the tablets to the child, } \\
\text { but it didn't work. Seeing that, we decided } \\
\text { to take the child to traditional healers. } \\
\text { (Parent of a boy aged } 2 \text { years who died of } \\
\text { malaria) } \\
\text { - The child was yet to take traditional } \\
\text { medications when h/s died. This is } \\
\text { because I started by administering the } \\
\text { baby medications prescribed by health } \\
\text { professionals. (Parent of a boy aged } 1 \text { year } \\
\text { who died of malaria) } \\
\text { - He/she finished the meds but he/she } \\
\text { didn't recover. Then we said, "The child } \\
\text { might have been given poison. Let's go } \\
\text { for checking". When we had checked, we } \\
\text { found that the child had been poisoned but } \\
\text { it was too late to save his life. He/she died } \\
\text { that night. (Parent of a boy aged } 1 \text { year } \\
\text { who died of malaria (Kirehe)) }\end{array}$ & $\begin{array}{l}\text { They performed malaria test but the child tested } \\
\text { negatively for malaria. Following this, they asked } \\
\text { me to take the child to the people who could } \\
\text { perform consultations on the child to see if he/she } \\
\text { had 'ikimoso'. (Parent of a boy aged } 3 \text { years who } \\
\text { died of diarrhoea). } \\
\text { - The child fell ill but her condition didn't severely } \\
\text { deteriorate. I took the child to the public health } \\
\text { facility and then to the private health facility. The } \\
\text { child's illness persisted to such an extent that he/ } \\
\text { she couldn't eat anything at all! I tried to seek } \\
\text { treatment for the child but to no avail. (Parent of a } \\
\text { girl aged } 4 \text { years who died of HIV/AIDS) }\end{array}$ \\
\hline $\begin{array}{l}\text { Phase III excerpts by } \\
\text { COD domain }\end{array}$ & No divergent themes & \\
\hline
\end{tabular}

decisions to seek care as well as how it impacts decisions to follow-through with treatment plans.

CBHI was widespread and highly valued by our informants. However, there were implementation challenges. Informants discuss the high cost of insurance and share deeply concerning narratives of being turned away from health facilities with critically ill children. Caregivers also describe avoiding health facilities because of a fear of being turned away due to not having health insurance.

As is the nature of qualitative research and despite census-level data, the themes arising from these data cannot be assumed to be representative beyond the population studied. However, our analysis of a large sample helps illuminate concepts that should be considered and explored in parallel populations. Other limitations include variation in interviewing techniques due to multiple research assistants in the field as well as variable transcription of narratives. We minimised this issue through rigorous training of our research assistants, and regular research team debriefings during data collection and processing. Although several techniques for triangulating and identifying cases were used, it is possible that child death cases were missed due to relocation or misclassification. This could lead to a selection bias because unidentified cases may be systematically different from those that were analysed (eg, more remote, fewer resources, less likely to seek care). Our community-based triangulation methods were designed to capture the most marginalised families and to identify those that have left the catchment area after a child's death. Finally, our study is not powered to draw statistical conclusions from the descriptive data.

\section{CONCLUSION}

The patient narratives presented here describe the challenges that families face at home, in their communities and with the health system to provide their children with timely and appropriate medical care. Dramatic failures or gross indiscretions are rare. Parents and families describe making the decisions they thought were best and doing the most that they could despite barriers. The barriers and delays described by caregivers in this dataset are concentrated in the first and third phase, with a significant contribution from delays occurring after leaving a formal facility, a category of themes that we have termed phase IV delays. Using a four delays framework may help more fully characterise delays leading to the death of children in settings such as ours, because unlike maternal cases, definitive treatment for children often occurs after seeing a provider.

Rwanda has made exceptional progress in child health, meeting and exceeding MDGs. In order to maintain and accelerate this progress in the Sustainable Development Goals era, several approaches could be considered. Healthcare service delivery needs to be consistently and reliably aligned with national policies and would require improved facility-level accountability mechanisms to ensure that patients are not denied care or otherwise treated unfairly. Continued improvements in the quality of care, especially around provider competence in the areas of patient-centred care and communication, are necessary. Provider competencies should include the ability to form healing partnerships with patients to prevent poor adherence and the ability to explore and understand competing explanatory models that may cause delays in 


\section{Box 1 Illustrative care-seeking narrative}

- In September, the child started having a cough and fever. And whenever the child had cough and fever, I rushed to CHWs who gave me tablets for the child. As the tablets did not help they finally referred me to the health facility... One of the health professionals I found there told me, "You have to take the child to your nearest health centre for TB test". And when I took the child to my nearest health centre, they did not perform TB test. The child became sickly such that I was obliged to go to the health facility every week.

- When people saw that, they told me the child was victim of poisoning and asked me to take the child to those people who would pray for his recovery. When they told me that the child was suffering from poisoning, I took him/her to traditional healers who gave medications to the child. I spent there 2 weeks. After taking such medications, the child started having diarrhoea following which traditional healers told me, "The child has been poisoned". The traditional healers added, "As the child has started having diarrhoea after being given medications, it means that poison has been removed from the baby's body. Now, you have to take the child to the health facility for him/her to be put on drip so that the level of water in his body can be increased"

- I arrived [home] on a Saturday. On the following Monday, I said to myself, "I have to wash my clothes as I need to take the child to the health facility". However, the child's hair had started becoming very fine as if the child had kwashiorkor. The CHW said to me, "The child appears to be in a critical condition and I have to give you a referral note so that you can take him/her to the health facility" . The CHW reported that the child was suffering from malnutrition. However, I had adequate foods for my child. I had beans and often bought small fish commonly known as ' indagara'. I also used to buy soybeans and give the child porridge made up of a mixture of many ingredients. I had enough foods to feed my child.

- As the child's condition became very critical, I took the child to (HF $X)$. And when I arrived there, a health professional rushed to call an ambulance on looking at the child...A health professional checked the palms of the child's hands and his eyes and concluded that the child had anaemia. They immediately referred me to (HFY).

- I went to (HFY) nearly 2 months after the child started having cough. Even if I used to take the child to those who would pray for him/her, I didn't neglect seeking treatment from the health facility...I went to (HF Y) on the 26th day and stayed there for 23 days. This often happens when one is at the health facility. Whenever the child's condition became critical, I went to alert them but they appeared not to be interested in what I was telling them. If they had taken care of the child, I wouldn't have stayed for as many days at (HFY)...At the end of these 23 days, they told me that I had to take the child to Kigali... When we arrived, they laid the child on the bed and was examined. The child lost weight. This is because when I took the child to the health facility for his 9- month vaccination, the child weighed 10 $\mathrm{kg}$... The child weighed $3 \mathrm{~kg}$ at death. They then started feeding the child on milk... On the following Sunday, they stopped giving milk to the child and started feeding him/her on porridge...

- However, there later came a time when the child's condition started becoming very critical and the child would wake up every night crying out in pain...I went (back) to Kigali where they performed tests on the child and when I asked them, "What illness does the child have?", they turned a deaf ear to me. Around 7.00 one of the health professionals came to me and told me, "The child has little chance of survival. As you can see, the child is in a very critical condition. We're very sorry for that". I too was realising that the child was

\section{Box 1 Continued}

going to die. I asked him/her, "What illness does the child have?" $\mathrm{He} / \mathrm{she}$ told me that the child has pneumonia and that it was too late to save his life. It's really unclear to me which of these illnesses killed the child (Parent of a boy aged 1.5 years who died of AIDS).

Minor changes to the narrative were necessary to make the order of health facilities clear to the reader.

achieving good health outcomes. ${ }^{41}$ Finally, in order for caregivers to be partners in child health, they must have practical knowledge about appropriate care-seeking and be empowered to use it to help their children be healthy.

\section{Author affiliations}

${ }^{1}$ Global Health and Population, Harvard University T H Chan School of Public Health, Boston, Massachusetts, USA

${ }^{2}$ Ifakara Health Institute, Dar es Salaam, Dar es Salaam, United Republic of Tanzania ${ }^{3}$ Global Health Equity, Brigham and Women's Hospital, Boston, Massachusetts, USA

${ }^{4}$ Partners in Health/Inshuti Mu Buzima, Rwinkwavu, Rwanda

${ }^{5}$ Maternal Child and Community Health Rwanda Biomédical Center, Rwanda Ministry of Health, Kigali, Rwanda

${ }^{6}$ Ariadne Labs, Boston, Massachusetts, USA

${ }^{7}$ Northwestern University Feinberg School of Medicine, Chicago, Illinois, USA

Acknowledgements The authors gratefully acknowledge the data collectors and study staff for their dedication to collect the data with great sensitivity and compassion for the families involved in this study. The authors would like to thank hospital leadership and staff from Rwinkwavu and Kirehe District Hospitals and the many health workers who have committed their lives to caring for families in Rwanda. The authors would like to thank Harvard Catalyst, The Harvard Clinical and Translational Science Center (National Center for Research Resources and the National Center for Advancing Translational Sciences, National Institutes of Health Award UL1 TR001102) via mixed methods consulting services from Rebekka M Lee. (The content is solely the responsibility of the authors and does not necessarily represent the official views of Harvard Catalyst, Harvard University and its affiliated academic healthcare centers, or the National Institutes of Health.) The authors would like to thank the Doris Duke Charitable Foundation's African Health Initiative funding for this project. The authors would also like to thank the families and caregivers who generously shared their difficult stories to contribute to reducing U5 mortality in Rwanda.

Contributors Study oversight (LRH, NG), study design (LRH, NG, DMK, LH), data collection (LH, DMK), data coding (LH, SR-D), data analysis (SR-D, LRH), manuscript writing (SR-D), manuscript review (SR-D, NG, LH, DMK, EN, CM, TB, LRH).

Funding This study was funded by Doris Duke Charitable Foundation.

Competing interests None declared.

Patient consent for publication Not required.

Ethics approval Study approval was received from the Rwanda National Ethics Committee and Partners Health Care.

Provenance and peer review Not commissioned; externally peer reviewed.

Data sharing statement The datasets used and/or analysed during the current study are available from the corresponding author.

Open access This is an open access article distributed in accordance with the Creative Commons Attribution Non Commercial (CC BY-NC 4.0) license, which permits others to distribute, remix, adapt, build upon this work non-commercially, and license their derivative works on different terms, provided the original work is properly cited, appropriate credit is given, any changes made indicated, and the use is non-commercial. See: http://creativecommons.org/licenses/by-nc/4.0/.

\section{REFERENCES}

1. Musafili A, Essén B, Baribwira $C$, et al. Trends and social differentials in child mortality in Rwanda 1990-2010: results from three 
demographic and health surveys. $J$ Epidemiol Community Health 2015:69:834-40.

2. LÅ P, Rahman A, Peña R, et al. Child survival revolutions revisited lessons learned from Bangladesh, Nicaragua, Rwanda and Vietnam. 2017:871-7.

3. UNICEF. Levels and Trends in Child Mortality. New York, NY: United Nations Children's Fund, 2015.

4. Liu L, Oza S, Hogan D, et al. Global, regional, and national causes of under-5 mortality in 2000-15: an updated systematic analysis with implications for the Sustainable Development Goals. The Lancet 2016;388:3027-35.

5. UNICEF. Levels and Trends in Child Mortality: Report 2015. Estimates Developed by the UN Inter-agency Group for Child Mortality Estimation. New York, NY: United Nations Children's Fund, 2015.

6. Bojalil R, Kirkwood BR, Bobak M, et al. The relative contribution of case management and inadequate care-seeking behaviour to childhood deaths from diarrhoea and acute respiratory infections in Hidalgo, Mexico. Trop Med Int Health 2007;12:1545-52.

7. Waiswa P, Kallander K, Peterson S, et al. Using the three delays model to understand why newborn babies die in eastern Uganda. Trop Med Int Health 2010;15:964-72.

8. Noordam AC, Carvajal-Velez L, Sharkey AB, et al. Care seeking behaviour for children with suspected pneumonia in countries in sub-Saharan Africa with high pneumonia mortality. PLoS One 2015;10:1932-6203

9. Ingabire CM, Kateera F, Hakizimana E, et al. Determinants of prompt and adequate care among presumed malaria cases in a community in eastern Rwanda: a cross sectional study. Malar $J$ 2016;15:227.

10. Bensaïd K, Yaroh AG, Kalter HD, et al. Verbal/Social Autopsy in Niger 2012-2013: A new tool for a better understanding of the neonatal and child mortality situation. J Glob Health 2016:6:010602.

11. Manzi A, Magge H, Hedt-Gauthier BL, et al. Clinical mentorship to improve pediatric quality of care at the health centers in rural Rwanda: a qualitative study of perceptions and acceptability of health care workers. BMC Health Serv Res 2014;14:275.

12. Moh R. Republic of Rwanda: Health System, 2014. http://gov.rw/ services/health-system/2016.

13. Mugeni C, Levine AC, Munyaneza RM, et al. Nationwide implementation of integrated community case management of childhood illness in Rwanda. Glob Health Sci Pract 2014;2:328-41.

14. Mitsunaga T, Hedt-Gauthier BL, Ngizwenayo E, et al. Data for program management: An accuracy assessment of data collected in household registers by community health workers in Southern Kayonza, Rwanda. J Community Health 2015;40:625-32.

15. Makaka A, Breen S, Binagwaho A. Universal health coverage in Rwanda: a report of innovations to increase enrolment in communitybased health insurance. The Lancet 2012;380:S7.

16. National Institute of Statistics of R, Ministry of F, Economic PR, Ministry of HR, International ICF. Rwanda Demographic and Health Survey 2014-15: Kigali, Rwanda: National Institute of Statistics of Rwanda, Ministry of Finance and Economic Planning/Rwanda, Ministry of Health/Rwanda, and ICF International, 2016.

17. Nonyane BA, Kazmi N, Koffi AK, et al. Factors associated with delay in care-seeking for fatal neonatal illness in the Sylhet district of Bangladesh: results from a verbal and social autopsy study. J Glob Health 2016:6:010605.

18. Koffi AK, Maina A, Yaroh AG, et al. Social determinants of child mortality in Niger: Results from the 2012 National Verbal and Social Autopsy Study. J Glob Health 2016;6:010603.

19. Kalter HD, Yaroh AG, Maina A, et al. Verbal/social autopsy study helps explain the lack of decrease in neonatal mortality in Niger, 2007-2010. Journal of Global Health;6.
20. Njuki R, Kimani J, Obare F, et al. Using verbal and social autopsies to explore health-seeking behaviour among HIV-positive women in Kenya: a retrospective study. BMC Womens Health 2014;14:77.

21. Koffi Alain K, Babille M, Salgado R, et al. Social autopsy for maternal and child deaths: a comprehensive literature review to examine the concept and the development of the method. Population Health Metrics 2011;9:45.

22. D'Ambruoso L, Byass $\mathrm{P}$, Qomariyah $\mathrm{SN}$, et al. A lost cause? Extending verbal autopsy to investigate biomedical and sociocultural causes of maternal death in Burkina Faso and Indonesia. Soc Sci Med 2010;71:1728-38.

23. Hildenwall H, Tomson G, Kaija J, et al. "I never had the money for blood testing" - caretakers' experiences of care-seeking for fatal childhood fevers in rural Uganda - a mixed methods study. BMC Int Health Hum Rights 2008;8:12.

24. Kalter HD, Salgado R, Babille M, et al. Social autopsy for maternal and child deaths: a comprehensive literature review to examine the concept and the development of the method. Popul Health Metr 2011;9:45.

25. Bentley $\mathrm{B}, \mathrm{O}$ 'Connor $\mathrm{M}$. Conducting research interviews with bereaved family carers: when do we ask? J Palliat Med 2015;18:241-5

26. Dwyer SC, Jackson M. Qualitative bereavement research: incongruity between the perspectives of participants and research ethics boards AU - Buckle, Jennifer L. International Journal of Social Research Methodology 2010;13:111-25.

27. Verbal autopsy standards: The 2012 WHO verbal autopsy instrument Release Candidate 1. Geneva, Switzerland: World Health, Organization, 2012.

28. Thaddeus S, Maine D. Too far to walk: maternal mortality in context. Soc Sci Med 1994;38:1091-110.

29. Kruk ME, et al. High quality health systems - time for a revolution: Report of the Lancet Global Health Commission on High Quality Health Systems in the SDG Era Lancet Global Health, 2018.

30. Maxwell JA. Qualitative research design: an interactive approach. 3rd ed. Thousand Oaks: Calif, 2013

31. Creswell J. A Concise Introduction To Mixed Methods Research. Los Angeles: Sage Publications, 2015.

32. Curry L-S. Mixed Methods in Health Sciences Research: A Practical Primer. Applications and Illustrations of Mixed Methods Health Sciences Research. Thousand Oaks: SAGE Publications, Inc, 2017.

33. Saunders B, Sim J, Kingstone T, et al. Saturation in qualitative research: exploring its conceptualization and operationalization. Qual Quant 2018;52:1893-907.

34. Påfs J, Musafili A, Binder-Finnema P, et al. Beyond the numbers of maternal near-miss in Rwanda - a qualitative study on women's perspectives on access and experiences of care in early and late stage of pregnancy. BMC Pregnancy Childbirth 2016;16:257.

35. Kleinman A, Eisenberg L, Good B. Culture, illness, and care: clinical lessons from anthropologic and cross-cultural research. Ann Intern Med 1978;88:251.

36. Finel E. Fighting Against Epilepsy in Rwanda: An Efficient Patient Centred Experience, 2012

37. Ngang PN, Ntaganira J, Kalk A, et al. Perceptions and beliefs about cough and tuberculosis and implications for TB control in rural Rwanda. Int J Tuberc Lung Dis 2007;11:1108-13.

38. Beste J, Asanti D, Sirotin N, et al. Traditional Medicine Use in Pregnancy in Rural Rwanda, 2012:S846-S7.

39. Taylor CC. The concept of flow in Rwandan popular medicine. Soc Sci Med 1988;27:1343-8.

40. Donabedian A. The quality of care. How can it be assessed? JAMA 1988;260:1743-8.

41. Kleinman A, Benson P. Anthropology in the clinic: the problem of cultural competency and how to fix it. PLoS Med 2006;3:e294. 